\title{
THE BROADCASTING ON INTERNET OF WATER DPSIR INDICATORS EXPERIMENT ON THE NESTOS DELTA, GREECE
}

\section{A. KARAKOS ${ }^{1 *}$ \\ X. SKOULIKARIS 1 \\ J-M. MONGET² \\ H. JERRENTRUP 3}

\author{
${ }^{1}$ Department of Electrical and Computer Engineering \\ Democritus University of Thrace \\ Xanthi, Greece, GR 67100 \\ ${ }^{2}$ Centre d'Informatique Geologique \\ Ecole Nationale Superieure des Mines de Paris \\ Sophia-Antipolis, France, FR 06904 \\ ${ }^{3}$ EPO Living Lakes \\ Hrysoupoli, Greece, GR 54200
}

*To whom all correspondence should be addressed tel: +30 2541079755; fax: +30 2541079781

e-mail: karakos@ee.duth.gr
Selected from papers presented at the $8^{\text {th }}$ Conference

on Environmental Science and Technology,

8 - 10 September 2003, Lemnos, Greece.

\begin{abstract}
An initial GIS data base has been assembled in 2001 covering the various parameters related to the Nestos river basin and its delta. This data set is being used for water resources modelling purposes within the frame of the multinational PROMENES initiative. The initial data gathering has produced a vast set of information which has been stored using the ArcView GIS tool. The European Water Framework Directive (WFD) recently defined guidelines for structuring the GIS databases aimed at water resources management. It is stressing the use of "open" GIS systems and formats in order to further facilitate maintenance and reporting to the public, a needed requirement. The present project explores the application of the DPISR concept to the publication of a "State of the Environment Report" on the Nestos delta through Internet. This concept has recently been proposed by the European Environmental Agency and is already in application for air pollution indicators broadcasting and urban environmental problems reporting. The PROMENES data base has been restructured using an "open" GIS approach and lessons learned on how to organize water management related datasets for the building of environmental indicators. A prototype web site is evaluated and is being tested for public broadcast under the supervision of EPO Living Lakes, an environment protection organisation operating in the Nestos delta.
\end{abstract}

KEYWORDS: Mesta, Nestos, DPSIR, GIS database, Environmental report

\section{INTRODUCTION}

The PROMENES (PROject-MEsta-NEStos) initiative is as a long term multidiscipline $R \& D$ effort focusing on the Mesta/Nestos river basin and aimed at a better understanding of sustainability of watershed resources and the wise management of their socio-economic implications. Current and future capacity building programs 
funded by EU in the area of the Mesta/Nestos (PHARE and INTERREG) as well the application of the EU Water Framework Directive (WFD) should insure future proper regional monitoring of both water resources and water quality. The PROMENES aims at the effective use of these investments by proposing to develop efficient modelling techniques and to promote their usage in conjunction with economic instruments and decision support systems applied to the integrated water management of both the Mesta and the Nestos part of the watershed.

\section{GENERAL OVERVIEW}

Starting high in the Rila Mountains of Bulgaria, the Mesta river enters for the second half of its stream the Thrace region of Greece and changes name to be called Nestos. It plunges down towering canyons toward the Aegean Sea through mostly metamorphic formations. At the end, the main stream spreads over the coastal plain of Chrysoupolis and expands as a deltaic system with freshwater lakes and ponds forming the Nestos delta.
The entire catchment's of Mesta/Nestos is 5,751 sq. $\mathrm{km}$ of which the 2,314 sq. $\mathrm{km}$ lie in Greece and the rest in Bulgaria. This trans-boundary river basin is managed under a complex GreeceBulgaria treaty defining the amount of water flow from the Mesta river which is assigned to each of the two countries' consumption.

\section{DATA AND PROCEDURE}

The initial data gathering has produced a vast set of information which has been stored using the ArcView GIS tool. A small sample of this data research is showed on Figure 1, as a layout view, after their manipulation under the ArcView3.2 program. The data collection results from a six months research effort both in Greece and Bulgaria. The main sources for the Greek territory were: the Municipalities of Kavala and Xanthi (Departments of Agriculture and Fisheries), DUTH (Demokritus University of Thrace) Dept. of Civil Engineering and Dept. of Environmental Engineering, IGME (Geological Survey of Greece), DEH (Public Power

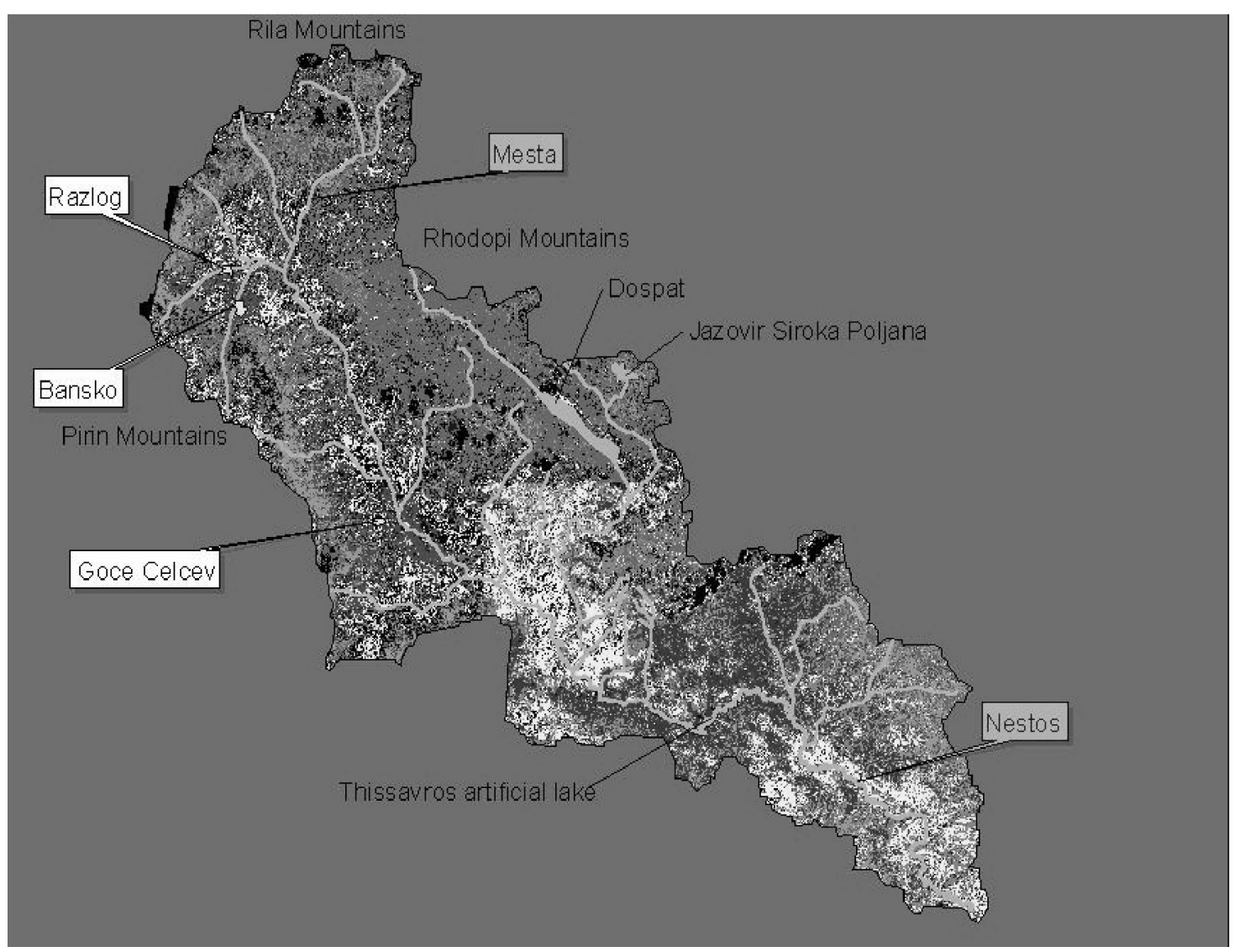

Figure 1. Overview of the Mesta-Nestos watershed 
Corporation of Greece), TOEV (Water Irrigation Company), the National Statistic Agency of Greece and EPO Living Lakes.

Our purpose was not only to publish multiple and precise geographic data but also to investigate their use as environmental indicators following the European Environment Agency directives. The concept of DPSIR indicators has recently been proposed by this agency and is already in application for air pollution indicators broadcasting and urban environmental problems reporting. It is also used in preparatory phase in Greece both for coastal water resources (ex: the Axios river within the EUROCAT project) and for land use planning (ex: the ESPON project from the Hellenic Ministry of Environment, Physical Planning and Public Works).

The final investigative step was and still is the recommendation of a publishing procedure on Internet. The European Water Framework Directive (WFD) recently defined guidelines for structuring the GIS databases aimed at water resources management. It is stressing the use of "open" GIS systems and formats in order to further facilitate maintenance and reporting to the public. But the main difficulty of GIS lies with the problem of data publication and update. As of today, it is still difficult to publish a GIS project on Internet. This is mainly because of the large data size and the difficulties of dynamically pointing to appropriate data paths. The solution to this problem lays in the systematic use of "open standards" such as the XML language or the "de facto" standards such the AutoCAD DXF format. Our project research has been aimed at identifying a practical and flexible solution to this problem of "open" GIS systems and it is divided into two main steps. At first, the export of ArcView attributes information to the Microsoft Access database and secondly the export of ArcView shape files to DXF format by using the Arcv2CAD 3.2 transfer tool or some other similar transfer tools. By this way all the data are captured outside of the GIS package and are stored in a server in appropriate form (XML language). The administrator work is limited to a regular update of the published data files and the public can access this information through the Web without the need of a particular GIS software. Although our platform is still under construction, the present effort has been based on the AxioMap tool.

\section{THE DPSIR METHOD}

The European Environment Agency is aiming at using environmental indicators in order to report on the progress of the environmental state of the European Union in a number of policy areas. This type of report is also aimed at assessing - with a limited selection of indicators - the reasons behind the rate of progress made in some of the main environmental policy areas. Another important aim of this concept is to raise questions, such as: why is there so much progress in country $\mathrm{X}$ and why have policy measures for problem Y not yet shown any result? In the coming years, the EEA and its Topic Centres will publish sets of indicators for each environmental issue dealt with by the EEA, based on the agreement of all participating countries.

\section{Indicator selection and presentation}

Although the EEA indicators and their analysis are placed within the DPSIR framework (Driving Forces - Pressure - State - Impact - Response; see Figure 2), no attempt has been made yet to provide indicators for each of the D-P-S-I-R categories. As most of the policy action is at the "Driving Forces" and the "Pressure" side of the causal chain, the most policy-relevant indicators show developments in these areas. Some EEA State indicators have been included because of public attention (e.g. increase in UV-radiation through depletion of the ozone layer) or because policies have quality targets (e.g. air pollution or global air temperature). "Response" indicators are usually difficult to provide due to a lack of data. However, they are included in a number of EEA chapters - stratospheric ozone depletion, wetlands and, of course, environmental taxes.

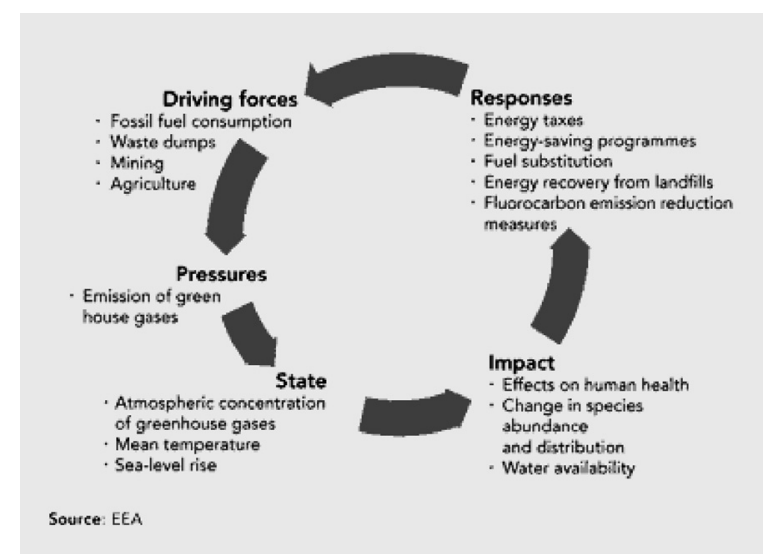

Figure 2. Example of DPSIR diagram for climate change 
Indicators that span DPSIR categories provide an insight into processes in the environment and the development of links between human activities and the environment.

\section{Why do we need environmental indicators?}

Communication is the main function of indicators: they should enable or promote information exchange regarding the issue they address. Our body temperature is an example of an indicator we regularly use. It provides critical information on our physical condition. Likewise, environmental indicators provide information about phenomena that are regarded typical for and/or critical to environmental quality. Communication demands simplicity. Indicators always simplify a complex reality. They focus on certain aspects which are regarded relevant and on which data are available. But their significance goes beyond that obtained directly from the observed properties. Environmental indicators communicate those aspects regarded as critical or typical for the complex interrelation between natural species and abiotic components of the environmental system. In relation to policy-making, the environmental indicators are used for three major purposes:

1. To supply information on environmental problems, in order to enable policy-makers to value their seriousness;

2. To support policy development and priority setting, by identifying key factors that cause pressure on the environment;

3. To monitor the effects of policy responses. In addition, environmental indicators may be used as a powerful tool to raise public awareness on environmental issues. Providing information on driving forces, impacts and policy responses, is a common strategy to strengthen public support for policy measures.

\section{The DPSIR framework}

At present, most indicator reports compile sets of physical, biological or chemical indicators. They generally reflect a systems analysis view of the relations between the environmental system and the human system. According to this systems analysis view, social and economic developments exert Pressure on the environment and, as a consequence, the State of the environment changes, such as the provision of adequate conditions for health, resources availability and biodiversity.
Finally, this leads to Impacts on human health, ecosystems and materials that may elicit a societal Response that feeds back on the Driving forces or on the state or impacts directly, through adaptation or curative action.

Obviously, the real world is far more complex than can be expressed in simple causal relations in systems analysis. There is arbitrariness in the distinction between the environmental system and the human system. And, moreover, many of the relationships between the human system and the environmental system are not sufficiently understood or are difficult to capture in a simple framework. Nevertheless, from the policy point of view, there is a need for clear and specific information on:

- Driving forces

- Resulting environmental Pressures

- the State of the Environment

- Impacts resulting from changes in environmental quality and on

- Societal Response to these changes in the environment.

In order to meet this information need, environmental indicators should reflect all elements of the causal chain that links human activities to their ultimate environmental impacts and the societal response to these impacts.

The DPSIR framework is useful in describing the relationships between the origins and consequences of environmental problems, but in order to understand their dynamics it is also useful to focus on the links between DPSIR elements. For instance, the relationship between the ' $D$ ' and the ' $\mathrm{P}$ ' by economic activities is a function of the ecoefficiency of the technology and related systems in use, with less 'P' coming from more ' $D$ ' if ecoefficiency is improving. Similarly, the relationship between the Impacts on humans or eco-systems and the 'S' depends on the carrying capacities and thresholds for these systems. Whether society 'Responds' to impacts depends on how these impacts are perceived and evaluated; and the results of ' $R$ ' on the ' $D$ ' depends on the effectiveness of the Response (Figure 3).

\section{INTERNET PUBLISHING PROCEDURE}

AxioMap is a software package for publishing and viewing interactive maps on the World Wide Web. It is based on XML, the eXtensible Markup Language which is an emerging standard for data interchange on the Internet. AxioMap is built in 


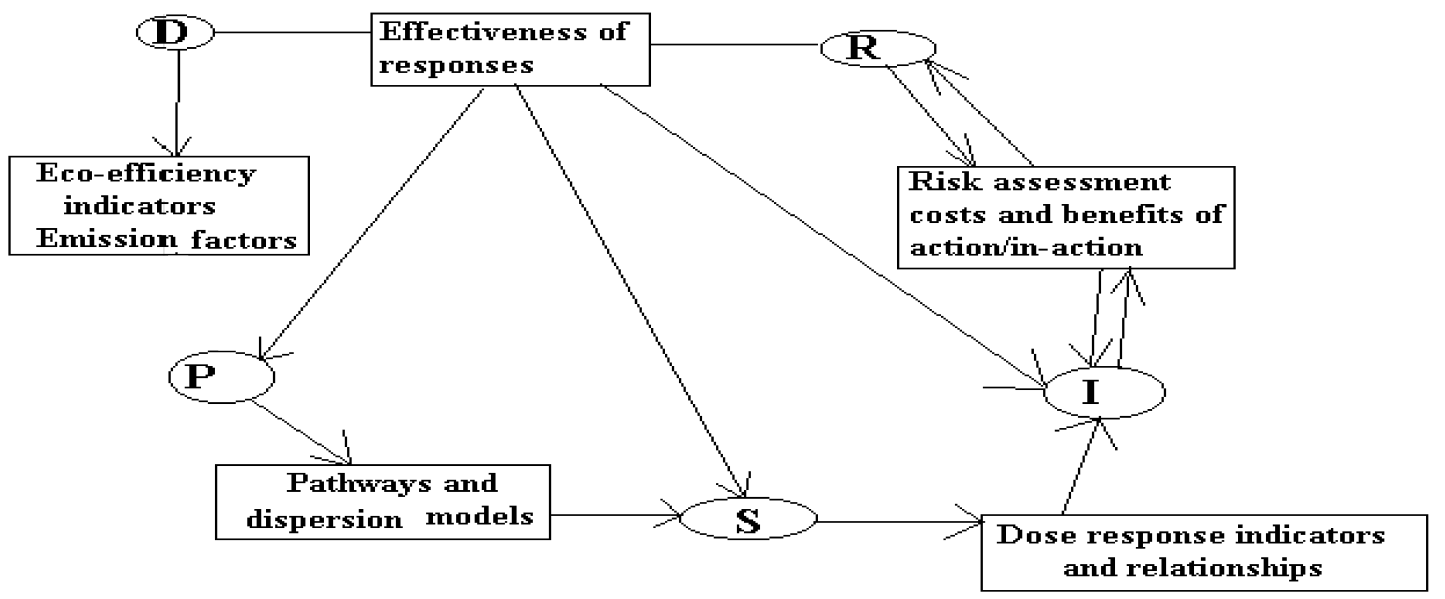

Figure 3. Indicators and information linking DPSIR elements

two parts: (1) an ArcView extension to allow quick and easy conversion of ArcView projects into a series of XML files with map information, and (2) an interactive map viewer that can display, in your Web browser, map information retrieved from these XML files.

\section{Layers}

As map layers are prepared for conversion, one needs to decide not only which layers will appear on the Web, but also whether these layers should be permanent, or will be displayed "on demand" by a user. AxioMap generally follows the layer organization of ArcView. An ArcView point, line, or polygontheme can be converted to a point, line, or area theme in XML, for use in AxioMap. One may want some layers to always appear on the map, if these layers create geographic context or represent essential information. In AxioMap, the layers that are permanently displayed on the map are built as a hierarchy of zero or more background layers, a unique base thematic layer, and zero or more foreground layers. Background layers are displayed below the base thematic layer, while foreground layers are displayed on top of it. In addition to permanent layers, AxioMap supports any number of point, line and polygon layers that users can choose to show or hide. These "add-on" layers are numbered sequentially from 0 upward and clustered by object type: point, line and polygons.

In addition to permanent layers, AxioMap supports any number of point, line and polygon layers that users can choose to show or hide. These "add-on" layers are numbered sequentially from 0 upward and clustered by object type: point, line and polygons. For example, if you have 5 point layers, they will have numbers $0,1,2,3$ and 4 . The point layer number 0 is the bottom-most of all point layers.

AxioMap layers are drawn in the following order: background layers (at the bottom) - the base thematic layer - foreground layers - polygon layers line layers - point layers - base area labels - addon graphics such as individual labels and buffers (on top). This hierarchy is presented in the scheme below.

Based on the construction script, and starting from an initial view of Nestos irrigation area with ArcView (Figure 4), we have undertaken a particular publishing exercise which presents the Nestos delta irrigated area (Figure 6) and offers the possibility to build combined maps by selecting from a list of items: shell farms, lagoons, fisheries, Nestos river bed and irrigation system thus leading to the interactive construction of DPSIR indicators.

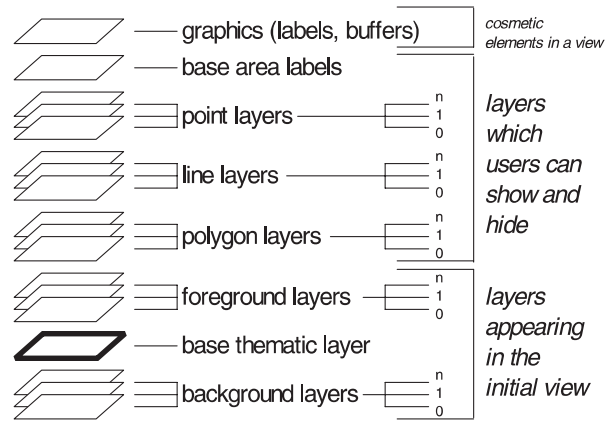

Figure 4. Layers classification 


\section{CONCLUSIONS}

The main result of this work has been to produce an experimental Internet publishing of part of the PROMENES GIS project. During this work the main difficulties laid in the development of the exporting procedures transforming .shp files into a .dxf format. The reconstruction of the "open" version of the GIS around Microsoft Access and DXF files was also particularly cumbersome because huge attribute files had to be manipulated. Of course, there were also some parts that worked almost immediately, like the ODBC connection of the attribute files to the Access data base.
At time of publication our project research approaches its final target. We have gathered all the information of the Mesta-Nestos basin and we have built our GIS schemes using the ArcView tool. In addition, all the data are stored in separate databases outside ArcView, as well as, the shape files content. As far as the DPSIR concept is concerned, we have enough data for the Driving forces and Pressure indicator and we continue getting data for the State indicator, so as to be able to evaluate the Impact and the Response contributions. The original purpose of constructing one platform for publishing on Internet DPSIR indicators in a deltaic environment are near completion.

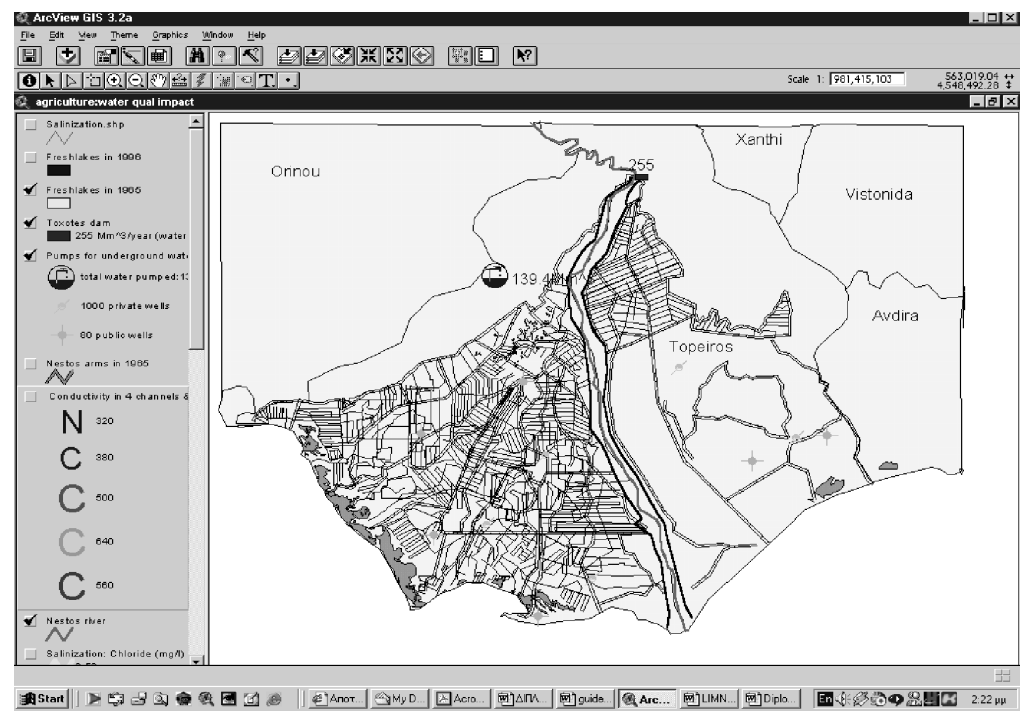

Figure 5. The initial view in ArcView 3.2

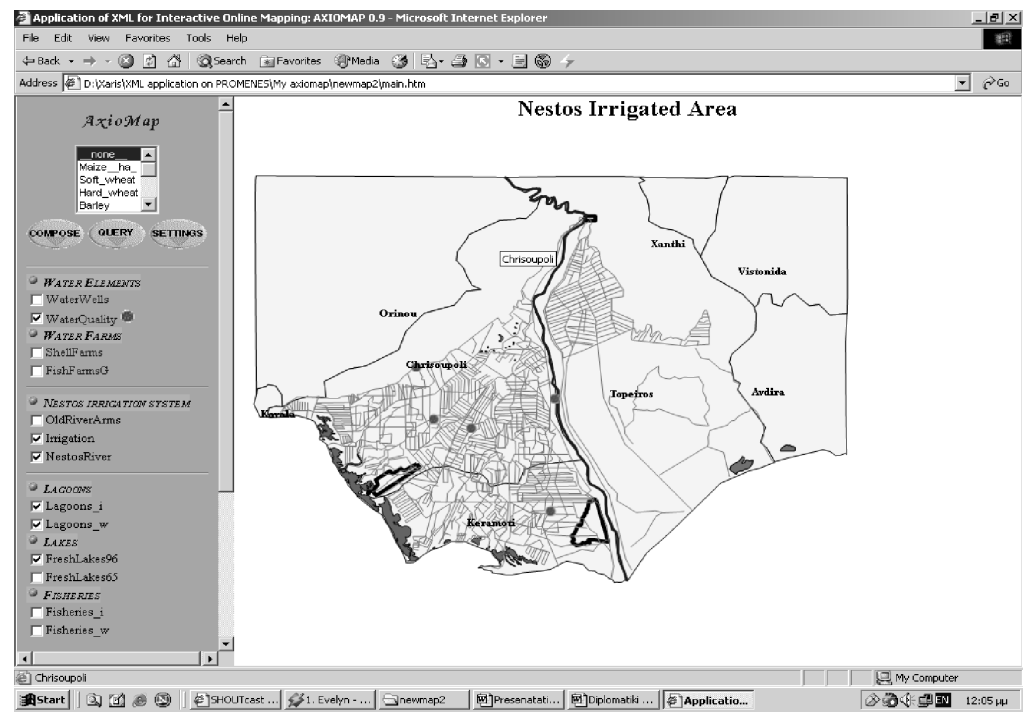

Figure 6. Published View on a Web browser page 


\section{REFERENCES}

Edith Smeets, Rob Weterings, (1999) Environmental indicators, Typology and overview at http://reports.eea.eu.int/TEC25/en/tech_25_text.pdf

European Environment Agency, (1998) at http://reports.eea.eu.int/signals-2000/en/page002.html

Extension tools Arc/View 3.x, (2002), at http:/www.uni-tuebingen.de/uni/egi/studium/projekte/schaeuble/sites/shape.htm Jochen Jesinghaus, (1999) Indicators for Decision-Making, at http://esl.jrc.it/envind/idm/idm_e_.htm

The evaluation version of Arcv2CAD, (2001), at http://www.guthcad.com.au/download.htm XML based GIS, (2001), at http://www.elzaresearch.com/landv/axiomap_ie5.html

PROMENES: Mesta/Nestos Water Resources Observatory. A cooperative research initiative. Edited by J-M Monget, Centre d'Informatique Geologique - Ecole National Superieure des Mines de Paris, France and A. Karakos, Department Electrical and Computer Engineering, Democritus University of Thrace, Greece

Viavattene C. (2001), The Mesta-Nestos basin. Study of a cross-border water basin. Diplome Europeen d'Etudes Superieures en Sciences et Education en Environnement, University of Rennes, France and University of Thessaloniki, Greece. 2001

Fallon A., Towards sustainable water management in the European Union countries, a focused study on the Nestos delta, Greece, in parallel with a French case, the Marais Poitevin. Diplome Europeen d'Etudes Superieures en Sciences et Education en Environnement, University of Rennes, France and University of Thessaloniki, Greece. 2001

Skoulikaris X., GIS data management for water resources monitoring, Diploma of Electrical and Computer Engineering, Democritus University of Thrace, Greece. 2002 